\title{
Patient experiences of a physiotherapy-led multidisciplinary rehabilitative intervention after successful treatment for oesophago-gastric cancer
}

\author{
Annemarie Bennett \\ Trinity College Dublin, Ireland, abennet@tcd.ie \\ L. O'Neill \\ Trinity College Dublin, Ireland \\ D. Connolly \\ Trinity College Dublin, Ireland
}

See next page for additional authors

Follow this and additional works at: https://arrow.tudublin.ie/scschbioart

Part of the Oncology Commons, and the Physiotherapy Commons

\section{Recommended Citation}

Bennett, A.E., O'Neill, L., Connolly, D. et al. Patient experiences of a physiotherapy-led multidisciplinary rehabilitative intervention after successful treatment for oesophago-gastric cancer. Support Care Cancer 26, 2615-2623 (2018). DOI: 10.1007/s00520-018-4112-6

This Article is brought to you for free and open access by the School of Biological Sciences at ARROW@TU Dublin. It has been accepted for inclusion in Articles by an authorized administrator of ARROW@TU Dublin. For more information, please contact arrow.admin@tudublin.ie, aisling.coyne@tudublin.ie,gerard.connolly@tudublin.ie. Funder: Health Research Board, Ireland 


\section{Authors}

Annemarie Bennett, L. O'Neill, D. Connolly, E. M. Guinan, L. Boland, Suzanne Doyle, J. O'Sullivan, J. V. Reynolds, and J. Hussey 


\title{
Patient experiences of a physiotherapy-led multidisciplinary rehabilitative intervention after successful treatment for oesophago-gastric cancer
}

\author{
A. E. Bennett ${ }^{1}$ (D) L. O'Neill ${ }^{2} \cdot$ D. Connolly ${ }^{3}$ E. M. Guinan ${ }^{4} \cdot$ L. Boland ${ }^{3} \cdot$ S. L. Doyle ${ }^{5} \cdot$ J. O$^{\prime}$ Sullivan $^{6} \cdot$ J. V. Reynolds $^{6} \cdot$ \\ J. Hussey ${ }^{2}$
}

Received: 11 November 2017 / Accepted: 11 February 2018 / Published online: 18 February 2018

(C) Springer-Verlag GmbH Germany, part of Springer Nature 2018

\begin{abstract}
Purpose To qualitatively explore the perceived impact of a 12-week rehabilitative intervention for oesophago-gastric cancer survivors on their physical, mental and social wellbeing.

Methods Of the 21 participants who completed the intervention, 19 took part in a semi-structured focus group interview. Four audio-taped focus groups were held, ranging in size from two to eight participants. Focus groups were transcribed and analysed using a descriptive qualitative approach.

Results At recruitment, participants were $23.5 \pm 15.2$ months post-surgery and all had suboptimal fitness levels. Participants reported improvements in their physical capacity and ability to carry out activities of daily living during the intervention. These improvements led to increased confidence and social connectivity. Other participants were a valuable source of information and reassurance, while support from family members was variable. Future interventions should educate participants on how to maintain gains achieved during the intervention.

Conclusions Participating in an exercise-based multidisciplinary rehabilitative intervention reduces isolation and helps oesophago-gastric cancer survivors to safely negotiate their physical, emotional and social needs as they move further down the path of recovery.
\end{abstract}

Keywords Rehabilitation · Exercise · Physiotherapy · Oesophageal cancer · Gastric cancer · Confidence

\section{A. E. Bennett}

abennet@tcd.ie

1 Department of Clinical Medicine, School of Medicine, Trinity Centre for Health Sciences, Dublin 8, Ireland

2 Discipline of Physiotherapy, School of Medicine, Trinity Centre for Health Sciences, Dublin 8, Ireland

3 Discipline of Occupational Therapy, School of Medicine, Trinity Centre for Health Sciences, Dublin 8, Ireland

4 School of Medicine, Trinity Centre for Health Sciences, Dublin 8 , Ireland

5 School of Biological Sciences, Dublin Institute of Technology, Kevin Street, Dublin 8, Ireland

6 Department of Surgery, School of Medicine, Trinity Centre for Health Sciences, Dublin 8, Ireland

\section{Background}

Curative treatment for oesophago-gastric cancer is invasive [1] and often poses challenges in the wake of surgery, such as reduced physical function [1-5], digestive problems [4, 6], fatigue [7], isolation $[4,8,9]$ and a compromised quality of life $[2,4,10]$. Such challenges can persist for years [4], forcing patients to simultaneously manage physical and psychosocial complications related to their treatment.

Since treatment complications span multiple domains of wellbeing, efforts to address them must be multidisciplinary in nature. It is well-acknowledged $[4,5,11,12]$ that there is a need to develop rehabilitation interventions which address the manifold needs of oesophago-gastric cancer survivors. However, rehabilitative research in this area has largely been limited to periods shortly before and after treatment [1]. In recognition of this, a 12-week exercise-based multidisciplinary rehabilitative intervention was designed for survivors who 
had completed treatment for oesophago-gastric cancer at least 6 months previously [5, 13].

Several studies have reported the benefits of participating in group exercise after completing cancer treatment [12, 14-19]. Quantitative data provide valuable insights into what constitutes safe exercise for different groups of cancer survivors. However, to optimise the design, implementation and uptake of rehabilitative interventions, participant experiences must be considered [18]. Therefore, qualitative data should be amassed to ensure that an intervention is tailored to the needs of participants.

This study aimed to qualitatively explore participant experiences of a 12-week multidisciplinary rehabilitative intervention for oesophago-gastric cancer survivors. Of particular interest was the perceived impact of the intervention on physical, mental and social wellbeing.

\section{Methods}

This study was part of a convergent parallel mixed methods study design [20]. It was designed to complement the findings of the RESTORE randomised controlled trial (RCT), and as such, a qualitative descriptive (QD) approach was taken [21, 22]. This approach describes individuals' perceptions of phenomena and is appropriate for informing the delivery of interventions [23].

\section{Recruitment}

Participants in the intervention arm of the RESTORE (Rehabilitation Strategies following Oesophago-Gastric Cancer) RCT were invited to take part in a focus group. This 12-week intervention was run on four occasions, facilitating 21 participants. There were no withdrawals or drop-outs. In week 10 of the intervention, participants were invited to provide feedback through a focus group. Participants were given 2 weeks to consider the invitation and to provide informed written consent to participate in a focus group on the last day of the intervention. Participants were eligible to participate if they had completed the intervention and had no evidence of cancer recurrence; all participants met these criteria.

\section{Rehabilitative intervention}

The target population was individuals who had undergone an oesophagectomy or gastrectomy with curative intent in the previous 5 years. Individuals from this population who had medical approval to complete exercise testing and to participate in prescribed exercise were eligible to take part.
The intervention aimed to improve physical function and quality of life, with particular emphasis on increasing participant capacity to achieve recommended physical activity levels $[5,24]$. The 12-week intervention consisted of 14 exercise sessions with a physiotherapist, individually prescribed exercise for home, sessions with a dietitian and education talks on recovery.

Supervised exercise sessions included a warm-up, a 20-35 min of aerobic exercise prescribed at $30-60 \%$ of heart rate reserve, a low/moderate intensity $(<75 \%$ 1-repetition max) resistance training programme [25] and a cool-down. Supervised aerobic exercise increased in intensity and duration as the intervention progressed and was completed on a treadmill, stationary bike or crosstrainer. Home exercise was monitored with a Polar Heart Rate Monitor (PolarFT7, China). A dietitian assessed patients to ensure they remained weight stable. Education talks were delivered by a surgeon, physiotherapist, dietitian, occupational therapist, cancer nurse and cancer support centre representative.

\section{Data collection}

Four focus groups were held between July 2016 and February 2017. Focus groups were solely facilitated by an occupational therapist (DC or LB) who had delivered one educational talk and who had experience of conducting focus groups with oncology patients [26].

A semi-structured QD approach was taken [27]. The discussion topics were pre-determined, but as each topic was explored, questions were asked for more detail. The discussion focused on: the impact of the intervention on daily living, facilitators and barriers to exercise and group exercise and education. Discussions were audio-recorded and were, on average, 46 (range 36-55) minutes long.

\section{Data analysis}

Interviews were transcribed verbatim. Braun and Clarke's 6stage approach to thematic analysis [20] was used to analyse transcripts. Four authors (AEB, LON, DC and EG) individually analysed all transcripts. Each author followed the same process for analysis using nVivo 11 (QSR International, Australia), where codes were systematically generated across the full data set and arranged into potential themes, coded extracts were re-checked to ensure they were congruent with the theme to which they had been assigned and themes were reviewed to ensure that they were clearly defined. A high level of agreement was apparent when the coded transcripts were compared and consensus was reached on final themes and interpretations. 


\section{Results}

Nineteen participants (Table 1) took part, with focus groups ranging in size from two to eight participants. Four main themes and 10 subthemes were identified following data analysis (Table 2).

\section{Impact on the individual}

All participants had suboptimal fitness levels upon commencing the intervention, and many reported noticing positive changes in their fitness and endurance as the intervention progressed:

"And, over the weeks I've found that for the 30 minutes I'm going a lot further than when I started, and you're saying, 'Didn't get this far the first time.'” [RESTORE11]

Participants reported others noticing, and responding positively to, their increased fitness. One participant described how his sons' attitudes changed in light of his participation in the intervention:

"The thing I noticed is my two sons - who are into sport - you know, if there was anything going on, I wouldn't get the phone call, but now I'm getting the calls, 'We're going to this game or that game or the other game.' So, kind of their expectations have raised." [RESTORE02]
While undoubtedly pleased with these physical changes, many participants were taken aback by the gains experienced, having underestimated the capacity of their body to recover:

"I suppose I was pleasantly surprised that I was able to do more, you know? I don't know whether it's partexcuse or what the last few years has thrown at us, that I kind of maybe had convinced myself that I wasn't able to do a lot." [RESTORE01]

Overcoming physical challenges previously believed to be insurmountable contributed to a more positive outlook on wellbeing. Participants discussed having fewer selfdeprecating thoughts and more confidence being physically active:

"It gave you an idea that there is a good living, you can live good now after it [treatment]. The negativity is gone in me - I can't say 'I'm not able' or 'That's wrong if you do that, you're lifting too much or you're doing too much'. You can do it." [RESTORE09]

They also reported feeling more confident and motivated to carry out general activities of daily living:

"It gave you more confidence in getting you doing stuff, you know? You're not saying, 'Oh, I'll leave it, I'll do it

Table 1 Characteristics of 19 oesophago-gastric cancer survivors participating in focus groups

\begin{tabular}{|c|c|c|c|c|c|}
\hline Study ID & Gender & Age (years) & Cancer type & $\begin{array}{l}\text { Time since } \\
\text { surgery (months) }\end{array}$ & Employment status \\
\hline RESTORE01 & Female & 54 & Oesophageal & 62 & Employed full-time \\
\hline RESTORE02 & Male & 74 & Oesophageal & 30 & Retired \\
\hline RESTORE04 & Male & 74 & Oesophageal & 23 & Retired \\
\hline RESTORE07 & Male & 81 & Oesophageal & 44 & Retired \\
\hline RESTORE08 & Male & 65 & Oesophageal & 10 & Employed part-time \\
\hline RESTORE09 & Male & 74 & Oesophageal & 35 & Retired \\
\hline RESTORE11 & Male & 61 & Oesophageal & 23 & Retired \\
\hline RESTORE13 & Female & 63 & Oesophageal & 37 & Retired \\
\hline RESTORE16 & Male & 57 & Oesophageal & 12 & Employed part-time \\
\hline RESTORE23 & Male & 71 & Oesophageal & 17 & Retired \\
\hline RESTORE26 & Male & 58 & Oesophageal & 8 & Employed full-time \\
\hline RESTORE29 & Male & 64 & Gastric & 16 & Retired \\
\hline RESTORE30 & Male & 63 & Oesophageal & 10 & Employed full-time \\
\hline RESTORE31 & Male & 74 & Oesophageal & 36 & Retired \\
\hline RESTORE33 & Female & 68 & Oesophageal & 42 & Retired \\
\hline RESTORE36 & Male & 63 & Oesophageal & 8 & Retired \\
\hline RESTORE39 & Male & 74 & Oesophageal & 9 & Employed part-time \\
\hline RESTORE40 & Male & 80 & Oesophageal & 16 & Semi-retired \\
\hline RESTORE41 & Female & 67 & Oesophageal & 7 & Retired \\
\hline
\end{tabular}


Table 2 Themes and subthemes developed from focus groups on participating in a rehabilitative intervention

\begin{tabular}{|c|c|c|}
\hline Themes & Subthemes & Codes \\
\hline \multirow[t]{16}{*}{ Impact on the individual } & \multirow[t]{4}{*}{ Physical condition } & Improved fitness \\
\hline & & Improved sleep quality \\
\hline & & Others noticing positive physical change \\
\hline & & Physical capacity better than expected \\
\hline & \multirow[t]{6}{*}{ Positive psychosocial effect } & Increased confidence and positivity \\
\hline & & Less defeatist thinking \\
\hline & & Losing the 'patient label' \\
\hline & & Providing proof of recovery to family \\
\hline & & Becoming more sociable \\
\hline & & Sense of achievement \\
\hline & \multirow[t]{3}{*}{ Experience of fatigue } & Acquiring an understanding of fatigue \\
\hline & & Reduction in fatigue \\
\hline & & Adopting strategies to manage fatigue \\
\hline & \multirow[t]{3}{*}{ Dietary intake } & Acquiring new knowledge on diet \\
\hline & & Improved dietary intake \\
\hline & & Less anxiety around diet \\
\hline \multirow[t]{5}{*}{ Participating in an intervention } & \multirow[t]{2}{*}{ Facilitators of participation } & Intervention tailored to individual capacity \\
\hline & & Encouragement from staff \\
\hline & \multirow[t]{3}{*}{ Challenges during participation } & Difficulty of increasing exercises \\
\hline & & Resistance to exercise \\
\hline & & Family anxiety over increasing exercise \\
\hline \multirow[t]{4}{*}{ Supportive relationships } & \multirow[t]{2}{*}{ Relationships with other participants } & Sharing experiences and information \\
\hline & & Feeling encouraged by peers \\
\hline & \multirow[t]{2}{*}{ Relationships with staff } & Helpful guidance from staff \\
\hline & & Encouraged, but not pushed \\
\hline \multirow[t]{4}{*}{ Intervention recommendations } & \multirow[t]{4}{*}{ Intervention structure and delivery } & Help sustain exercise after intervention \\
\hline & & Value of assigned exercise for home \\
\hline & & Duration and number of sessions \\
\hline & & More time for information exchange \\
\hline
\end{tabular}

tomorrow.' You know now it's important to keep going, get on with it." [RESTORE36]

Participants also credited their increased activity levels with reduced fatigue. They adopted exercise-based strategies to attenuate fatigue, with one participant highlighting the value of short walks:

"I just go out, maybe I go to the shop - I don't buy anything but I just get out of the house - and I come back fresh as a daisy!" [RESTORE23]

Alleviating fatigue increased some participants' motivation to participate in the intervention:

"They said the exercise would help and it was hard to believe, because you think it'll make you more tired, but it didn't. It actually worked and the fatigue really lifted.
So I was looking forward to coming here every time it was on - I was counting the time when it was on again!" [RESTORE08]

Participants also discussed how their involvement in the intervention defied the 'patient label', and provided proof of recovery which encouraged others to include them once again in social activities:

"You're sick, the person is 'sick' if you're recovering from an operation. Like, they leave you recovering for 20 years or something! But they'll say now, 'Sure he climbed that thing [participant climbed a mountain during the intervention]. Bring him up, he's no problem'. So eventually they get it and you re-join, you're no longer an invalid or a patient for the rest of your life." [RESTORE08] 
One participant who had worked in a physically demanding job prior to his diagnosis reported that the physical and mental benefits experienced during the intervention catalysed his return to work:

"With me personally, it's actually got me back to work. I had been thinking about it and thinking about it and thinking about it! But that was as far I got, you know? The impetus from this project and just feeling that wee bit better, I just thought, 'Yeah, let's take that jump."” [RESTORE16]

\section{Participating in an intervention}

While participants reported having to exert themselves to complete their exercises, they observed that the physiotherapist prescribed exercises which suited their capacity:

"The girls were tough but fair. There's no point in being a wimp - they have to push you, but they knew your limits." [RESTORE11]

However, some reported struggling with the week-onweek increases in exercise targets:

"The targets that are being set for you every week, you know, there, there's no downward slope, it's an upward slope all the time. You don't seem to reach a steady point, and if you can stay there, you're happy. It, it's ever upwards, you know? I found it pretty hard to, to achieve." [RESTORE16]

Despite this, many participants recognised the value of exercising beyond their 'comfort zone':

"Even though sometimes they were very tiring, at the same time I think it gave us a fresh look to say, 'Well, look at the positive side rather than the negative side.' There's so many people that tell you, 'Sit down and don't do anything,' 'Take it easy, you're after being through a lot.' And now we have the confidence, to say, 'Go and do it.'" [RESTORE09]

Although many participants' confidence in their physical abilities increased, family members did not always share this confidence. One participant adopted measures to hide the fact that he had been doing household chores from his partner, who he described as caring for him like he was 'ten babies':

"As soon as she's [his partner] gone into town, the brush is out and I'm in the garden, and I'm snipping the little bits and putting them in a bag in the bottom of the bin so she won't see them!" [RESTORE40]

Conversely, others reported receiving encouragement from family throughout their participation, which increased their motivation to reach their exercise targets:

"She [daughter] would be a good motivator. She'd say 'The bike,' 'Are you going out?' or 'Get a half hour in before the match' or something like that. So it has been a double sort of thing." [RESTORE01]

\section{Supportive relationships}

The support of fellow participants was deemed invaluable. Many participants spoke of the isolation they felt, with some never having met another person with the same diagnosis prior to the intervention:

"I had never met anybody with oesophagus cancer. People would say to me, 'Where the hell is your oesophagus?!'” [RESTORE33]

In light of this, participants discussed the support they received through having access to others with relatable symptoms:

"You know, you're having something going on that wouldn't happen before the operation, and you're thinking, 'Is this back now? Is this something?' Then you'll hear someone here say, 'Yeah, I get that as well,' and you're saying, 'Oh. That's alright, then.' It's reassuring." [RESTORE11]

It was also acknowledged that a 'very good atmosphere' with 'a good bit of banter' had evolved, making it easy to exchange information and interact with those leading the intervention.

\section{Intervention recommendations}

When asked for suggestions for improvement, participants often focused on measures to help them sustain the gains achieved. They emphasised the value of exercise prescribed for home, recognising its importance for seeing advances in fitness levels:

"God yeah, I think if you hadn't the homework, you'd do nothing until the next session." [RESTORE23]

Given the identified value of 'homework', participants queried the possibility of occasional visits back to the centre or of 
remote monitoring of physical activity after the intervention, to sustain motivation:

"I know that once I don't have the 'Big Brother is watching me,' to, you know, if I could convince myself that if I kept running that monitor, somebody is checking the data, you know?" [RESTORE01]

"If you had these monitors at home and you were, say, by 11 o'clock, you have to have your readings in and they [physiotherapists] were able to read these from you at home. Even though it's at a distance, you can send it in over the net or something, and she can see that you did it." [RESTORE08]

Most participants felt that the number and duration of sessions were appropriate; a small minority would have liked more than 14 sessions, but no one wanted fewer sessions. Given the emphasis placed upon peer support, some participants recommended more time for discussion during the education talks:

"You could certainly do with a little bit more time for asking questions and kind of sharing, just generally sharing the information." [RESTORE13]

Participants remarked that they have a wealth of knowledge specific to oesophago-gastric cancer to offer. They believed that when the opportunity arises to share this knowledge, every effort should be made to take advantage of the value of exchanging information:

"We actually have a lot of knowledge. Sometimes I'd go to my GP, but because I'd know so much about this now, I can tell him things! So I think we shouldn't underestimate the knowledge that we've gained. So, just having the opportunity to share information around is crucial." [RESTORE01]

\section{Discussion}

This is the first study to explore the experiences of oesophagogastric cancer survivors who participated in a multidisciplinary rehabilitative intervention. The findings indicate that participating in such an intervention had important physical, mental and social benefits for those involved.

One of the principal benefits experienced - and from which many other benefits stemmed - was improved physical function. Treatment for oesophago-gastric cancer may induce weight loss, muscle loss and sarcopenia [3,28], all of which compromise physical function [1, 5, 28]. Furthermore, oesophago-gastric cancer survivors often experience longterm complications such as fatigue, pain and diarrhoea $[3,8$, 29], complications which undoubtedly make it difficult to restore physical function without professional guidance $[4,11$, 30]. It has been reported [31] that less than $25 \%$ of cancer survivors meet physical activity guidelines [24], and with the fitness levels of all participants in this study classed as suboptimal, the potential for improvement in physical function was significant. The positive changes in function reported here are similar to those described in other studies $[12,17,18$, 31], with participants reporting increased fitness, a higher capacity to carry out activities of daily living and reduced fatigue.

Many participants expressed surprise at their enhanced physical performance, having become habituated to doubting their physical capacity. Since oesophago-gastric surgery has traumatic consequences for physical health [1, 4, 32], a loss of faith in physical capacity is understandable [15, 33-35]. However, the potentially negative consequences on mental outlook emphasises the need to help patients reclaim losses in physical function as soon as possible after surgery [4, 32]. Exercise-based rehabilitation has been credited with returning a sense of ownership to cancer survivors over an area of their health which has, in many respects, been managed by other individuals [11, 14, 18, 19, 36, 37]. Similarly, several participants in this study viewed exercise as a way of reclaiming their body [12] and creating distance from the status of "cancer patient' [37].

As their physical performance improved, participants observed that they felt less negative and more confident. Cancer survivors often hover between feeling hopeful for a cancerfree future and feeling dread in the face of recurrence [4]. They have been reported to try and resist negativity by adopting measures which help them to take control of daily living and pursue normality [38]. Participation in this intervention was a tangible effort to regain the means to live more productively and take charge of some pre-diagnosis responsibilities. Given the numerous references to improved confidence among this group, it is clear that regaining some of the physical losses experienced during treatment can have a profound effect on an individual's confidence and perceived self-worth [35, 38].

Several participants reported experiencing positive changes in their social connectivity as their physical wellbeing and mental outlook improved. A cancer diagnosis often invokes some manner of disconnect within a person's social network $[4,17]$, where treatment and complications can lead to more restricted living circumstances, potentially resulting in isolation and a reduced quality of life $[4,9]$. Several participants used their physical and mental gains to shed the 'patient label' and to prove to their social network that they were capable of resuming pre-diagnosis activities. Social support independently predicts health-related quality of life $[9,39]$ and encourages adherence to rehabilitative measures [40], making access to 
informed social support invaluable. Some participants emphasised the role of family in ensuring that they adhered to their prescribed exercises, whilst others highlighted the higher expectations of those around them in relation to their capacity to participate in everyday activities. Conversely, the family members of a small number of participants continued to doubt their physical capacity to the point of impeding their return to pre-diagnosis activities. Given the documented benefits of social support $[14,17,19]$, it may be necessary to address the concerns and knowledge gaps of family members at the outset of interventions such as this one, so that participants can fully benefit from the rehabilitation provided.

Although challenges were sometimes experienced in amassing family support, the support of fellow participants was unanimously deemed helpful. The opportunity to exchange information with others in a similar situation fostered a shared identity and a sense of reciprocal concern among the groups [15]. This solidarity [17, 19] alleviated some of the isolation participants had felt, with several highlighting that the intervention was the first time they had met others with a similar diagnosis. Peer support is a recognised benefit of group exercise $[12,16,41,42]$ and is especially beneficial among small groups [17], as there were in this study.

When asked for suggestions to improve the intervention, participants focused on sustaining their improved fitness, making suggestions of remote monitoring of physical activity and of visits back to the research centre. Since their enhanced fitness originated within a supervised environment, their reluctance to forgo this environment is understandable [31]. An increased motivation to be active has been reported for up to 5 years after an exercise intervention ends [43]. Therefore, as part of its design, a future intervention could teach participants to identify and manage barriers to exercise once the intervention ends [33]. Feedback in this study highlighted the need to empower participants to identify supports which help them to sustain improvements beyond the intervention $[16,31]$.

Before concluding, a number of methodological considerations must be highlighted. The results highlight the perceived benefits of participation and provide insights into some psychosocial benefits of participation which can be difficult to quantify [35]. To encourage candid feedback, discussions were facilitated by individuals who had had only one interaction with participants prior to the focus groups. Transcripts were systematically analysed [20,44] by four authors and a high level of agreement was reached on final themes and interpretations. Finally, the COREQ criteria [45] were used to ensure that the study was comprehensively presented.

\section{Conclusion}

This study explored the experience of participating in a multidisciplinary rehabilitative intervention designed for individuals who had been successfully treated for oesophago-gastric cancer. The recovery of this population is complex and addressing their myriad needs warrants a multidisciplinary approach which helps participants to safely negotiate their physical, emotional and social needs as they move further down the path of recovery.

Acknowledgements The authors wish to acknowledge the support and assistance of the Wellcome Trust HRB Clinical Research Facility, which is a dedicated environment for the conduct of research activities in St. James' Hospital. The authors also wish to thank the study participants for kindly agreeing to take time to participate in this study.

Funding information This study was funded by the Health Research Board (grant number HRA-POR-2014-535).

\section{Compliance with ethical standards}

Ethical approval was granted by the St James's Hospital-Tallaght Hospital joint ethics committee.

Conflict of interest The authors declare that they have no conflict of interest.

Informed consent Informed consent was obtained from all participants included in the study.

\section{References}

1. Tatematsu N, Hasegawa S, Tanaka E, Sakai Y, Tsuboyama T (2013) Impact of oesophagectomy on physical fitness and health-related quality of life in patients with oesophageal cancer. Eur J Cancer Care 22:308-313. https://doi.org/10.1111/ecc. 12030

2. Clarke C, McCorry NK, Dempster M (2011) The role of identity in adjustment among survivors of oesophageal cancer. J Health Psychol 16(1):99-108. https://doi.org/10.1177/1359105310368448

3. Elliott JA, Doyle SL, Murphy CF, King S, Guinan EM, Beddy P, Ravi N, Reynolds JV (2017) Sarcopenia: prevalence, and impact on operative and oncologic outcomes in the multimodal management of locally advanced esophageal cancer. Ann Surg 266:822-830. https://doi.org/10.1097/sla.0000000000002398

4. Malmstrom M, Ivarsson B, Johansson J, Klefsgard R (2013) Longterm experiences after oesophagectomy/gastrectomy for cancer-a focus group study. Int J Nurs Stud 50:44-52. https://doi.org/10. 1016/j.jinurstu.2012.08.011

5. O'Neill L, Guinan E, Doyle SL, Elliott JA, O'Sullivan J, Reynolds JV, Hussey J (2017) Rehabilitation strategies following esophageal cancer (the ReStOre trial): a feasibility study. Dis Esophagus 30:18. https://doi.org/10.1093/dote/dow012

6. Wainwright D, Donovan JL, Kavadas V, Cramer H, Blazeby JM (2007) Remapping the body: learning to eat again after surgery for esophageal cancer. Qual Health Res 17:759-771. https://doi.org/10. 1177/1049732307302021

7. Chang YL, Tsai YF, Wu YC, Hsieh MJ (2014) Factors relating to quality of life after esophagectomy for cancer patients in Taiwan. Cancer Nurs 37:4-13. https://doi.org/10.1097/NCC. 0b013e318277dc53

8. Scarpa M, Valente S, Alfieri R, Cagol M, Diamantis G, Ancona E, Castoro C (2011) Systematic review of health-related quality of life 
after esophagectomy for esophageal cancer. World J Gastroenterol 17:4660-4674. https://doi.org/10.3748/wjg.v17.i42.4660

9. Smith JD, Shuman AG, Riba MB (2017) Psychosocial issues in patients with head and neck cancer: an updated review with a focus on clinical interventions. Curr Psychiatry Rep 19:56. https://doi. org/10.1007/s11920-017-0811-9

10. Reynolds JV, McLaughlin R, Moore J, Rowley S, Ravi N, Byrne PJ (2006) Prospective evaluation of quality of life in patients with localized oesophageal cancer treated by multimodality therapy or surgery alone. Br J Surg 93:1084-1090. https://doi.org/10.1002/bjs. 5373

11. Malmstrom M, Klefsgard R, Johansson J, Ivarsson B (2013) Patients' experiences of supportive care from a long-term perspective after oesophageal cancer surgery - a focus group study. Eur J Oncol Nurs 17:856-862. https://doi.org/10.1016/j.ejon.2013.05. 003

12. Midtgaard J, Hammer NM, Andersen C, Larsen A, Bruun DM, Jarden M (2015) Cancer survivors' experience of exercise-based cancer rehabilitation - a meta-synthesis of qualitative research. Acta Oncol 54:609-617. https://doi.org/10.3109/0284186x.2014. 995777

13. Guinan EM, Doyle SL, O'Neill L, Dunne MR, Foley EK, O'Sullivan J et al (2017) Effects of a multimodal rehabilitation programme on inflammation and oxidative stress in oesophageal cancer survivors: the ReStOre feasibility study. Support Care Cancer 25:749-756. https://doi.org/10.1007/s00520-016-3455-0

14. Bulmer SM, Howell J, Ackerman L, Fedric R (2012) Women's perceived benefits of exercise during and after breast cancer treatment. Women Health 52:771-787. https://doi.org/10.1080/ 03630242.2012.725707

15. Korstjens I, Mesters I, Gijsen B, van den Borne B (2008) Cancer patients' view on rehabilitation and quality of life: a programme audit. Eur J Cancer Care 17:290-297. https://doi.org/10.1111/j. 1365-2354.2007.00864.x

16. Luoma ML, Hakamies-Blomqvist L, Blomqvist C, Nikander R, Gustavsson-Lilius M, Saarto T (2014) Experiences of breast cancer survivors participating in a tailored exercise intervention - a qualitative study. Anticancer Res 34:1193-1199

17. Malcolm L, Mein G, Jones A, Talbot-Rice H, Maddocks M, Bristowe K (2016) Strength in numbers: patient experiences of group exercise within hospice palliative care. BMC Palliat Care 15:97. https://doi.org/10.1186/s12904-016-0173-9

18. Spence RR, Heesch KC, Brown WJ (2011) Colorectal cancer survivors' exercise experiences and preferences: qualitative findings from an exercise rehabilitation programme immediately after chemotherapy. Eur J Cancer Care 20:257-266. https://doi.org/10.1111/ j.1365-2354.2010.01214.x

19. Stevinson C, Fox KR (2006) Feasibility of an exercise rehabilitation programme for cancer patients. Eur J Cancer Care. 15:386-396. https://doi.org/10.1111/j.1365-2354.2006.00677.x

20. Braun V, Clarke V (2006) Using thematic analysis in psychology. Qual Res Psychol 3:77-101. https://doi.org/10.1191/ 1478088706qp063oa

21. Sandelowski M (2000) Whatever happened to qualitative description? Res Nurs Health 23:334-340

22. Sandelowski M (2010) What's in a name? Qualitative description revisited. Res Nurs Health 33:77-84. https://doi.org/10.1002/nur. 20362

23. Neergaard MA, Olesen F, Andersen RS, Sondergaard J (2009) Qualitative description - the poor cousin of health research? BMC Med Res Methodol 9:52. https://doi.org/10.1186/14712288-9-52

24. Thompson PD, Arena R, Riebe D, Pescatello LS (2013) ACSM's new preparticipation health screening recommendations from ACSM's guidelines for exercise testing and prescription, ninth edition. Curr Sport Med Rep 12:215-217. https://doi.org/10.1249/ JSR.0b013e31829a68cf

25. Strasser B, Steindorf K, Wiskemann J, Ulrich CM (2013) Impact of resistance training in cancer survivors: a meta-analysis. Med Sci Sport Exer 45:2080-2090. https://doi.org/10.1249/MSS. 0b013e31829a3b63

26. Schwarz M, Landis SE, Rowe JE, Janes CL, Pullman N (2000) Using focus groups to assess primary care patients' satisfaction. Eval Health Prof 23:58-71. https://doi.org/10.1177/ 01632780022034480

27. Milne J, Oberle K (2005) Enhancing rigor in qualitative description: a case study. J Wound Ostomy Continence Nurs 32:413-420

28. Gannon JA, Guinan EM, Doyle SL, Beddy P, Reynolds JV, Hussey J (2017) Reduced fitness and physical functioning are long-term sequelae after curative treatment for esophageal cancer: a matched control study. Dis Esophagus 30:1-7. https://doi.org/10.1093/dote/ $\operatorname{dox} 018$

29. Awad S, Tan BH, Cui H, Bhalla A, Fearon KC, Parsons SL et al (2012) Marked changes in body composition following neoadjuvant chemotherapy for oesophagogastric cancer. Clin Nutr 31:74 77. https://doi.org/10.1016/j.clnu.2011.08.008

30. Williams K, Steptoe A, Wardle J (2013) Is a cancer diagnosis a trigger for health behaviour change? Findings from a prospective, population-based study. Brit J Cancer 108:2407-2412. https://doi. org/10.1038/bjc.2013.254

31. Adamsen L, Andersen C, Lillelund C, Bloomquist K, Moller T (2017) Rethinking exercise identity: a qualitative study of physically inactive cancer patients' transforming process while undergoing chemotherapy. BMJ Open 7:e016689. https://doi.org/10.1136/ bmjopen-2017-016689

32. van der Leeden M, Huijsmans R, Geleijn E, de Lange-de Klerk ES, Dekker J, Bonjer HJ et al (2016) Early enforced mobilisation following surgery for gastrointestinal cancer: feasibility and outcomes. Physiotherapy 102:103-110. https://doi.org/10.1016/j.physio.2015. 03.3722

33. Cho D, Park CL (2017) Barriers to physical activity and healthy diet among breast cancer survivors: a multilevel perspective. Eur J Cancer Care 27:e12772. https://doi.org/10.1111/ecc.12772

34. May AM, Korstjens I, van Weert E, van den Borne B, HoekstraWeebers JE, van der Schans CP et al (2009) Long-term effects on cancer survivors' quality of life of physical training versus physical training combined with cognitive-behavioral therapy: results from a randomized trial. Support Care Cancer 17:653-663. https://doi.org/ 10.1007/s00520-008-0519-9

35. Missel M, Pedersen JH, Hendriksen C, Tewes M, Adamsen L (2016) Regaining familiarity with own body after treatment for operable lung cancer - a qualitative longitudinal exploration. Eur J Cancer Care 25:1076-1090. https://doi.org/10.1111/ecc.12383

36. Cheng KKF, Lim YTE, Koh ZM, Tam WWS (2017) Home-based multidimensional survivorship programmes for breast cancer survivors. Cochrane Database Syst Rev 8:Cd011152. https://doi.org/10. 1002/14651858.CD011152.pub2

37. McGrath P, Joske D, Bouwman M (2011) Benefits from participation in the chemo club: psychosocial insights on an exercise program for cancer patients. J Psychosoc Oncol 29:103-119. https:// doi.org/10.1080/07347332.2010.532301

38. McCorry NK, Dempster M, Clarke C, Doyle R (2009) Adjusting to life after esophagectomy: the experience of survivors and carers. Qual Health Res 19:1485-1494. https://doi.org/10.1177/ 1049732309348366

39. Howren MB, Christensen AJ, Karnell LH, Funk GF (2013) Psychological factors associated with head and neck cancer treatment and survivorship: evidence and opportunities for behavioral medicine. J Consult Clin Psychol 81:299-317. https://doi.org/10. 1037/a0029940 
40. Aizer AA, Paly JJ, Zietman AL, Nguyen PL, Beard CJ, Rao SK, Kaplan ID, Niemierko A, Hirsch MS, Wu CL, Olumi AF, Michaelson MD, D'Amico AV, Efstathiou JA (2012) Multidisciplinary care and pursuit of active surveillance in lowrisk prostate cancer. J Clin Oncol 30:3071-3076. https://doi.org/ 10.1200/jco.2012.42.8466

41. Newby TA, Graff JN, Ganzini LK, McDonagh MS (2015) Interventions that may reduce depressive symptoms among prostate cancer patients: a systematic review and meta-analysis. PsychoOncology 24:1686-1693. https://doi.org/10.1002/pon.3781

42. Szalai M, Szirmai A, Fuge K, Makai A, Erdelyi G, Premusz V et al (2017) Special aspects of social support: qualitative analysis of oncologic rehabilitation through a belly dancing peer support group. Eur J Cancer Care 26. https://doi.org/10.1111/ecc.12656

43. Trinh L, Mutrie N, Campbell AM, Crawford JJ, Courneya KS (2014) Effects of supervised exercise on motivational outcomes in breast cancer survivors at 5-year follow-up. Eur J Oncol Nurs 18: 557-563. https://doi.org/10.1016/j.ejon.2014.07.004

44. Sandelowski M (1995) Qualitative analysis: what it is and how to begin. Res Nurs Health 18:371-375

45. Tong A, Sainsbury P, Craig J (2007) Consolidated criteria for reporting qualitative research (COREQ): a 32-item checklist for interviews and focus groups. Int J Qual Health Care 19:349-357. https://doi.org/10.1093/intqhe/mzm042 